\title{
A expansão do ensino médio e a educação de jovens e adultos: alternativa negligenciada de democratização?
}

\author{
Candido Al berto Gomes \\ Beatrice Laura Carnielli \\ Isolêta Rodrigues Assunção
}

Palavras-chave: ensino médio; educação dejovens eadultos; democratização da educação: distorção série-idade; ensino noturno.

\section{Resumo}

Caracteriza a expansão recente do ensino médio por meio do ensino regular e da educação de jovens eadul tos (EJA), investigan do os efeitos da el evação do li mite etário para a conclusão do curso via EJA. Para isso, consi dera que a educação éinternamente estratificada, com uma hierarquia de currícul os e modal idades educacionais, conforme seu prestígio e possi bilidades ocupacionais e sociais. Anal isa os dados dos últimos censos escol ares e conclui que o crescimento das matrículas, via EJA, foi mais rápido que no ensino regular; porém, partindo de uma base muito menor. No entanto, no quadro retratado pel os censos escolares, queabrange parteda EJA, o ensino regular tem permanecido uma preferência expressa dos al unos com distorção série/idade, tendo-se indícios de uma competição entre a EJA e o ensino regular noturno. Possivel mente, em virtude do seu menor prestígi o social, de li mitações qual itativas e resistências do mercado de trabaIho, a EJA pode estar deixando de contribuir, com a sua flexibilidade, para maior democratização educacional.

\section{Introdução}

O ensino médio experimentou notável crescimento recente, que podelevál lo a um novo status. Intimamente relacionado ao ensino fundamental e, inclusive, dependente deste, do ponto de vista da gestão, do pessoal e das instalações, a expansão da matrícula o tem levado a assumi r uma identidade própria. Pel o seu porte e pelas suas características, já se torna cada vez mais difícil viver de sobras dos recursos do ensino fundamental, precisando encontrar seus caminhos: éa história do patinho feio recontada (Gomes, 2000). É importante, porém, conhecer como essa expansão setem processado, quer pela modal idade do ensino regular, quer pela EJA, no quadro mais amplo da educação básica. Como última etapa desta, desemboca no ensino médio a distorção série/idade acumulada desde o ensino fundamental. Com isso, évultoso o contingente de al unos com mais de 17 anos de idade.

A Lei deDiretrizeseBases (Lei no 9.394/ 96), ou Lei Darcy Ribeiro, reduziu os limites de idade para conclusão do ensino fundamental e médio, via EJA, respectivamente, de 18 para 15 e de 21 para 18 anos. A decisão do legislador certamente se fundamentou no fato de que os indicadores de fracasso escol ar eram dramáticos evinham se reduzindo lentamente. Em especial, entreas evidências depesquisa, o Saeb/95 (Brasil, 1998) deixou claro que houve uma perda de proficiência dos al unos em todas as disciplinas, séries e regi ões pesquisadas, à medi da que aumentou a distorção série/idade. Isto é, o prolongamento da permanência no ensino regular não levava à mel horia do rendimento, mas à sua queda e à saída do aluno da escola. O dilema consistia em 
facilitar a saída de al unos do ensino regular ou prol ongar a sua agonia num sistema marcado pela denominada pedagogia da repetência. Tanto o prol ongamento dos estudos, em idade avançada para a série (a ponto de, pelo menos, dois terços da matrículainicial estarem desajustados), quanto o seu abandono puro esimples têm custos para o indivíduo ea col eti vidade. Paga o primeiro pelanão-obtenção de competências e certificados, paga a sociedade por privar-sedepessoal com mais al to nível de escol aridadee ainda concorre com o pagamento de impostos e contribuições que sustentam a educação pública. O legislador, diante desse quadro econtando com salvaguardas relativas ao padrão de quali dade, à avaliação e ao financiamento, decidiu-se pelo rebaixamento daquel es limites etários. Todavia, incompreensões el itistas se fizeram presentes na trami tação do Projeto de Lei, acusando-o deabrir um "facilitário" para a conclusão de estudos, quando o intuito legal sempre foi o de tornar a educação de jovens e adul tos um caminho de qual idade, adequado para a maturidade dos seus al unos (cf. Gomes, 1998; Cunha, 1998). ${ }^{1}$ No caso do ensino médio, é de se esperar que, pel a el evada distorção série/idade, a al ternativa da educação dejovens eadultos venha a ser amplamenteutilizada para o prosseguimento ea conclusão dos estudos.

\section{A estratificação interna da educação}

O paradigma do confl ito em sociologia da educação, por meio de numerosas tendências teóricas, tem destacado as disparidades educacionais e sociais e as suas relações mutuamentereforçadoras. Em seguida a uma série de pesquisas macrossociológi cas, a chamada nova sociologia da educação, surgi da no Reino Unido, na década de 70 do século 20 , fez uma crítica aos model os de in put-output para a análise das relações entre educação e estratificação social. Foi, então, proposta uma nova abordagem, vol tada para o conteúdo da educação e o funcionamento da escola. O currículo foi considerado como uma seleção deconhecimentos, aprovados pelasociedadee distribuídos a diversos grupos sociais em dosagens diferentes (Young, 1971). A primeira etapa da sel eção consiste na escol ha dos conteúdos da cultura considerados necessários e adequados aos estudantes. Além disso, o conhecimento é dividido em setores de status mais emenos altos, demodo que o currículo éestratificado em matérias segundo o seu prestígio. Assim, as matérias de mais al to status estão associadas a mai ores recompensas etendem a ser reservadas aos al unos "mais capazes". A cultura escolar, portanto, não é neutra, mas representa uma construção legi timando uma perspectiva cultural particular, que favorece uns e desfavorece outros.

A distribuição do conhecimento aos estudantes, conformea composição curricular, conduz a diversos ramos, com variados destinos sociais. Por exemplo, a educação profissional, com sua frontei ra menos rígida entre o conhecimento educacional eo conhecimento cotidiano, tem sido um ramo tradicional mentereservado aos al unos "mai sfracos". Combasenestas contribuições, estudos clássicos têm acompanhado as trajetórias diversificadas que se traçam nos sistemas educacionais, com recrutamento e sel eção mai sou menos explícitos esuaves dealunos para currículos e cursos de mai or ou menor prestígio, em idades variáveis, com implicações de estigmatização no relacionamento entreeducadores eeducandos edestes entre si (p. ex.: Kerckhoff, 1974; Rosenbaum, 1976; Cicourel, 1978). Mesmo os sistemas unitários, que não permitem diferenças explícitas entre ramos, diferenciam os currícul os por escola e por turma, agregando os alunos al egadamente segundo suas possi bilidades intel ectuais e, de acordo com grande parte das pesquisas, conformesuas origens sociais (Riordan, 2004).

A nova sociologia da educação tevecurta duração, mas o mesmo não sepode dizer da anál ise sociológica do currículo. Young (1988) reconheceu que a corrente apresentou al gumas fraquezas, a exemplo do insustentável tratamento do trabal ho acadêmico como fonteautônoma de mudança educacional. Fez também uma crítica das fontes teóricas e das direções para aprofundar as análises. Por seu lado, Bernstein (1990), prosseguindo com o enfoque estruturalista, desenvol veu seu modelo de prática pedagógica, conectando as rel ações de classee poder com os processos educacionais e os microprocessos escol ares com as forças sociais einstitucionais complexas.

A partir dos anos 80, a sociologia da educação tomou um cami nho mais pragmático, voltado para o conhecimento ou a expertise sobre a escola. A perspectiva da experiênciaescolar, centradana socialização

\footnotetext{
O legislador seresponsabiliza, no projeto dediplomalegal, porinserir as providênciasesal vaguardasnecessárias ao cumprimento dasuaintençãoedosseusobjetivos. Não faz sentido supor que leisorçamentárias, por exemplo, e, sobretudo, asua execução, no futuro deixarão deobedecer aos critérios determinados. Tal suposição corresponderia a negar ordenamentojurídico. Paratanto, entre outros mecanismos, existemafiscal ização eo controleeo próprio sistema deequilíbrioentreos Poderes incluindo aatuação do Ministério Público eaesperada pressão social.
} 
e na interação entre a cultura escolar e as dos al unos (de ambientes sociais populares ou favorecidos), destaca os efeitos das escolas, das turmas e dos professores, envolvendo, como não poderia deixar deser, as contradições entre os currícul os formal e real e a destinação mais ou menos sutil dos al unos aos diversos ramos do sistema escolar (cf. Dubet, Martuccelli, 1996; Barrère, Sembel, 2002).

Se estas formas de diferenciação dos currículos, obedecendo a hierarquias de prestígio e poder, conduzem a diversos destinos escol ares e sociais, segundo conjunto significativo de pesquisas, éde esperar que também tenham impacto diferentes modalidades de educação, como o ensino reguIar ea EJA. Esta última, como educação de segunda oportunidade, destina-seeminentemente aos alunos considerados "mais fracos", defasados e, portanto, menos privilegiados do ponto de vista social. Não é de surpreender que seus certificados sejam ol hados de esguel ha, atrel ados ao estigma do portador que não se deu bem no ensino regular ou que não pôde freqüentá-lo na idade própria.

Em outralatitudeteórica, quenão a do paradigma do conflito, texto clássico de Clark (1978) destaca as relações entre as organizações e os "valores precários", no caso da educação deadultos, embora o meio e certas condições sejam em parte diferentes do Brasil. Segundo o autor, os valores sociais tendem a ser precários, quando não incorporados claramente a objetivos e padrões existentes de grupos com el es comprometidos. A organização fica sujeita a dilemas e impasses na transformação dos seus val ores frente a problemas emergentes. Aplicando ao nosso caso, a EJA tem val ores precários por el es serem menos aceitáveis, não raro implícita ou vel adamente, por uma parte da população. Além dos problemas acima, trata-se de uma atividade menos vinculada ao propósito primário da educação, que tem como foco as crianças. A EJA é menos estruturada (embora isso seja intrínseco à sua fil osofia deadequar-se às características dos seus al unos); o ensino pode não ser compulsório, por haver sido ultrapassada a faixa de idade da obrigatoriedade escolar; sua procura é voIuntária, com o sustento dependente das oscilações do número de al unos; seus objetivos, em parte, são menos claros, por incluir não só a educação de segunda oportunidade, mas também toda a educação continuada, enquanto o seu caráter supletivo deixa-Ihe o sabor de prêmi o de consolação para quem não obteve sucesso escolar na idade própria. Essa precariedade de valores resulta num grau de legitimi dade mais baixo que o do ensino regular, numa posição relativamente marginal no âmbito organizacional e na maior dificuldade de obtenção de recursos. Por isso, não raro é vista como ônus nos orçamentos, tendendo a estar sujeita, por isso, a cortes mais severos quando a educação, como um todo, é pressionada. Seus obstáculos, por conseguinte, resultam das dificul dades relativas de aceitação e de legitimi dade em face do ensino regular, mais estruturado, bem situado na hierarquia escolar ecom imagem mais positiva entre o público.

Comefeito, pesquisa exploratória deâmbito reduzido no ensino público do Distrito Federal constatou o estigma daEJA pelo mercado detrabal ho, ao mesmo tempo em queos informantes assinalaram seu menor grau de exigência acadêmica, o quelimitava as possibilidades daquel es quetinhamaspirações educacionaiseocupacionais mais el evadas. A flexi bilidade e outras facilidades da EJA foram destacadas, porém eram consideradas mais apropriadas paraal unos com horizontes mais modestos. Desse modo, o sistema escolar se assemel hava a um mercado, que ofereciaum cardápio com diversas opções, caracterizadas por custosebenefíciosmaisou menos elevados (Gomes, Carnielli, 2003).

Considerado essestatus menos privilegiado da EJA, que se patenteia em nosso meio, inclusive pela al ocação de professores cedidos, pela improvisação no uso de instal ações do ensino regular e na fal ta de recursos próprios, cumpre indagar se, nas relações com o ensino regular, ela tem cumprido a função democratizadora que a Lei objetiva. Desse modo, emergem algumas questões degrande importância para as políticas educacionais que se del ineiam:

- Como setem caracterizado a expansão recentedo ensino médio, considerando o al to grau de distorção série/idade da sua população estudantil?

- Quais as tendências de crescimento da EJA em face do ensino regular?

- A redução do limiteetário de conclusão do ensino médio e fundamental, via EJA pela LDB, tem alcançado o seu propósi to deabrir nova al ternativa para alunos com atraso escolar concluírem seus cursos? 
- Como secaracterizam essas tendências nas matrículas segundo a região ea dependência administrativa?

No momento presente não é possível responder plenamente a várias destas questões. A principal limitação é a abrangência dos Censos Escolares, quenão têm podi do cobrir o chamado setor público não-governamental, quetem se esparramado por todo o País. Os Censos, real izados pelas Secretarias Estaduais de Educação, captamosal unos regularmentematriculados nos prédios escolares. Não conseguem cobrir os mais variados cursos oferecidos fora deestabel ecimentos deensino credenciados, nem os al unos de cursos para os quais as edi ficações públicas muitas vezes são cedidas. É como se el es trouxessem a visão de al gumas árvores do bosque que podem ou não ser representativas do todo. Assim, os dados censitários preliminares de 2003 dão conta de um total de 4.239 .475 matrículas na educação de jovens e adultos, sendo 281.831 na dependência particular. Há, entretanto, uma miríade não atingida de movimentos sociais, sindicatos, empresas, organizações não-governamentais e outras entidades que oferecem EJA. Só a Alfabetização Solidária (Alfabetização Solidária, 2003) contava com 563.822 al unos do chamado Módulo XIV, de julho a dezembro de 2003 , quase o dobro do recenseado para a iniciativa privada. Por sua vez, o Programa "Sesi - Educação do Trabal hador" al cançava, em 2000, nada menos que 991.051 alunos, da alfabetização ao ensino médio (Serviço Social dalndústria, 2001).
Por isso, o presente trabal ho pode antes contribuir para levantar indagações, bem como identificar lacunas que precisam ser preenchidas. Também não Ihe cumpreverificar seas decisões vislumbradas do al unado são ou não "corretas", mas procurar examinar a sua própria racional idade.

\section{Para onde vão o ensino médio e a educação básica?}

O ensino médio regular apresentou, nos últimos anos da década de 90, acentuado incremento da matrícula, quetal vez, esteja abrandando o seu ritmo (Tabela 1). Para isso, entretanto, é preciso conhecer o contexto da educação básica, da qual o ensino médio constitui a foz. O ensino fundamental reguIar da quinta à oitava série também experimentou um crescimento rápido, com o desrepresamento dos contingentes de alunos, antes em grande parte retidos pela reprovação e pelo abandono. Com isso, foi alimentado o crescimento do ensi no médio nos últimos anos, rumo à concretização da educação obrigatória de oito anos e da universal ização progressiva do nível médio.

Em contraste com a ascensão das matrículas do ensino médio e da quinta à oitava série da educação compulsória, a EJA, que começou a ser desagregada em 1997 pelos Censos Escolares, apresenta notória ascensão, em números índices, o que em grande partese devea uma base reduzida. Seu contingenteeratambém relativamentepequeno, mostrando que não foi o caminho por

Tabela 1 - Crescimento das matrículas, no ensino regular e EJA - Brasil - 1997-2002

\begin{tabular}{|c|c|c|c|c|c|c|}
\hline $\begin{array}{l}\text { Níveis e modalidades } \\
\text { de educação e ensino }\end{array}$ & 1997 & 1998 & 1999 & 2000 & 2001 & 2002 \\
\hline $\begin{array}{l}\text { Ensino médio e regular } \\
\mathrm{N}^{\circ} \mathrm{s} \text { índices }\end{array}$ & $\begin{array}{r}6.405 \\
100\end{array}$ & $\begin{array}{r}6.969 \\
109\end{array}$ & $\begin{array}{r}7.769 \\
121\end{array}$ & $\begin{array}{r}8.193 \\
128\end{array}$ & $\begin{array}{r}8.398 \\
131\end{array}$ & $\begin{array}{r}8.711 \\
136\end{array}$ \\
\hline $\begin{array}{l}\text { Ensino médio, EJA } \\
\mathrm{N}^{\circ} \mathrm{s} \text { índices }\end{array}$ & $\begin{array}{l}391 \\
100\end{array}$ & $\begin{array}{l}517 \\
132\end{array}$ & $\begin{array}{l}657 \\
168\end{array}$ & $\begin{array}{r}873 \\
22\end{array}$ & $\begin{array}{l}987 \\
252\end{array}$ & $\begin{array}{l}874 \\
224\end{array}$ \\
\hline $\begin{array}{l}\text { Ensino fundamental regular }-5^{a}-8^{a} \\
N^{0} \text { s índices }\end{array}$ & $\begin{array}{r}13.661 \\
100\end{array}$ & $\begin{array}{r}14.459 \\
106\end{array}$ & $\begin{array}{r}15.121 \\
111\end{array}$ & $\begin{array}{r}15.506 \\
114\end{array}$ & $\begin{array}{r}15.570 \\
114\end{array}$ & $\begin{array}{r}15.770 \\
115\end{array}$ \\
\hline $\begin{array}{l}\text { Ensino fundamental, EJA }-5^{a}-8^{a} \\
N^{\circ} \text { s índices }\end{array}$ & $\begin{array}{l}899 \\
100\end{array}$ & $\begin{array}{r}1.298 \\
144\end{array}$ & $\begin{array}{r}1.295 \\
144\end{array}$ & $\begin{array}{r}1.429 \\
159\end{array}$ & $\begin{array}{r}1.485 \\
165\end{array}$ & $\begin{array}{r}1.435 \\
160\end{array}$ \\
\hline $\begin{array}{l}\text { Ensino fundamental regular }-1^{a}-4^{a} \\
N^{\circ} s \text { índices }\end{array}$ & $\begin{array}{r}20.568 \\
100\end{array}$ & $\begin{array}{r}21.333 \\
104\end{array}$ & $\begin{array}{r}20.939 \\
102\end{array}$ & $\begin{array}{r}20.212 \\
98\end{array}$ & $\begin{array}{r}19.728 \\
96\end{array}$ & $\begin{array}{r}19.380 \\
94\end{array}$ \\
\hline $\begin{array}{l}\text { Ensino fundamental, EJA }-1^{a}-4^{a} \\
N^{\circ} s \text { índices }\end{array}$ & $\begin{array}{r}1.311 \\
100\end{array}$ & $\begin{array}{r}784 \\
60\end{array}$ & $\begin{array}{r}817 \\
62\end{array}$ & $\begin{array}{r}843 \\
64\end{array}$ & $\begin{array}{r}1.151 \\
88\end{array}$ & $\begin{array}{r}1.353 \\
103\end{array}$ \\
\hline
\end{tabular}


excelência da expansão do ensino. Os números índices dos cursos presenciais com avaliação no processo, com base em 1997, mostram, em 2002, quea matrículano nível médio atingia 224 nas séries finais do ensino fundamental, 160 enas suas séries iniciais, 103. Tendo como base também 1997, a matrícula nesses três níveis do ensino regular, em 2002, atingiu, respectivamente, 136, 115 e 94 . O cotejo mostra quea EJA cresceu mais proporcionalmente, porém, abrigando número rel ativamentemuito menor dealunos. Por outro lado, no ensino regular, o ensino médio apresenta o mai or crescimento, al iás constante, enquanto as séries finais do ensino fundamental crescem a um ritmo menor eas séries iniciaistendem ao declínio.
Por sua vez, a Tabel a 2 evidencia o avanço proporcional da EJA em relação ao ensino regular, embora dispondo de uma pequena participação, em face do total. No caso do ensino médio, nível que mais cresceu, a proporção quase dobrou nos cursos presenciais com aval iação no processo.

Pode-se, então, indagar a quem a EJA tem atendido e, se possível, em que proporções: a al unos que deixaram os estudos e estão buscando uma nova oportunidade ou a al unos que se atrasaram por sucessivas reprovações e/ou afastamento por abandono, tendo al cançado os limites de conclusão do ensino fundamental e médio estatuídos pela LDB? Como os Censos Escolares não acompanhama trajetória de cada

Tabela 2 - Percentual da matrícula da EJA sobre o ensino regular, por nível de ensino Brasil - 1997-2002

\begin{tabular}{|l|r|r|r|r|r|r|}
\hline \multicolumn{1}{|c|}{$\begin{array}{c}\text { Níveis e modalidades } \\
\text { de educação e ensino }\end{array}$} & \multicolumn{9}{|c|}{ Anos } \\
\cline { 2 - 8 } & 1997 & 1998 & 1999 & $\mathbf{2 0 0 0}$ & $\mathbf{2 0 0 1}$ & 2002 \\
\hline Ensino médio Regular (a) & 6.405 & 6.969 & 7.769 & 8.193 & 8.398 & 8.711 \\
\hline EJA (b) & 408 & 583 & 776 & 1.006 & 1.111 & $907^{*}$ \\
\hline B/a (\%) & 6,4 & 8,4 & 10,0 & 12,3 & 13,2 & 10,4 \\
\hline Ensino Fundamental Regular (a) & 34.229 & 35.793 & 36.060 & 35.718 & 35.298 & 35.150 \\
\hline EJA (b) & 2.255 & 2.177 & 2.241 & 2.405 & 2.774 & 2.830 \\
\hline B/a (\%) & 6,6 & 6,1 & 6,2 & 6,7 & 7,9 & 8,1 \\
\hline
\end{tabular}

Fonte dos dados originais: MEC/Inep/Seec

Nota: Números absolutos em milhares.

* Inclui somente cursos semipresenciais com avaliação no processo, de modo a preservar a série histórica.

aluno, não Ihes é possível responder integralmente a esta pergunta, ainda que possam oferecer uma aproximação, como se veráadiante.

Oferecendo uma dimensão das relações entre o ensino regular e a EJA, a Tabela 3 apresenta a distribuição percentual decada grupo etário segundo o nível ea modalidade de educação e ensino, bem como a da população recenseada, em 2000, nessas mesmas fai xas etárias.
Em primei ro lugar, aparece, com destaque, a el evada proporção dealunos defasados em relação ao nível de ensino, conhecido resul tado da pedagogia da repetência. Em segundo lugar, el evada proporção dos alunos do ensino fundamental, já defasados etariamente ( $56,7 \%$ do grupo de 15 a 17 anos) se mantinham no ensino regular e só $4,8 \%$ se achavam na EJA. Ainda, 30,8\% dos alunos de 18 a 24 anos estavam matriculados no ensino fundamental regular, assi m como 
Tabela 3 - Distribuição da população matriculada, em percentual, por grupos de idade, segundo o nível ea modalidade de educação e ensino - Brasil - 2000

\begin{tabular}{|c|c|c|c|c|c|}
\hline \multirow{2}{*}{$\begin{array}{c}\text { Matrículas por níveis } \\
\text { e modalidades de educação } \\
\text { e ensino }\end{array}$} & \multicolumn{5}{|c|}{ Grupos de idade (em anos) } \\
\hline & Até 14 & 15 a 17 & 18 a 24 & 25 a 29 & 30 e mais \\
\hline Ensino fundamental regular & 27.334 & 5.349 & 2.248 & 324 & 465 \\
\hline$\%$ & 99,5 & 56,7 & 30,8 & 27,2 & 25,5 \\
\hline Ensino médio regular & 66 & 3.565 & 3.893 & 350 & 320 \\
\hline$\%$ & 0,2 & 37,8 & 53,3 & 29,4 & 17,6 \\
\hline EJA: Alfabetização & 8 & 18 & 35 & 23 & 86 \\
\hline$\%$ & 0,0 & 0,2 & 0,5 & 1,9 & 4,7 \\
\hline Ensino fundamental & 81 & 451 & 765 & 320 & 655 \\
\hline$\%$ & 0,3 & 4,8 & 10,5 & 27,0 & 36,0 \\
\hline Ensino médio & 4 & 42 & 365 & 171 & 295 \\
\hline$\%$ & 0,0 & 0,5 & 4,9 & 14,5 & 16,2 \\
\hline Total & 27.493 & 9.425 & 7.306 & 1.188 & 1.821 \\
\hline$\%$ & 100,0 & 100,0 & 100,0 & 100,0 & 100,0 \\
\hline População recenseada & $27.125^{\star}$ & 10.703 & 23.379 & 13.850 & 71.604 \\
\hline Matrícula/população recenseada (\%) & $101,4^{* *}$ & 88,1 & 31,3 & 8,6 & 2,5 \\
\hline $\begin{array}{l}\text { Fonte dos dados originais: Censo Escolar, MEC/Ine } \\
\text { Observações: } \\
\text { - Números absolutos em milhares. } \\
\text { - EF: ensino fundamental; EM: ensino médio; EJA: } \\
\text { pois não foram divulgados dados da matrícula por ic } \\
\text { ensino fundamental e } 132 \text { mil no ensino médio. } \\
\text { - Números em negrito e itálico: percentuais de alun } \\
\text { * } 7 \text { a } 14 \text { anos de idade. } \\
\text { ** Número superior a } 100 \text { pela inclusão de alunos d }\end{array}$ & $\begin{array}{l}\text { Seec e Censo } \\
\text { mente educac } \\
\text { de dos cursos } \\
\text { defasados en } \\
\text { menos de sete }\end{array}$ & $\begin{array}{l}\text { ográfico, FIBC } \\
\text { jovens e adi } \\
\text { aratórios para } \\
\text { nos de série/ic } \\
\text { de idade. }\end{array}$ & $\begin{array}{l}\text { EJA: cursos } \\
\text { mes, que corr }\end{array}$ & $\begin{array}{l}\text { enciais com a } \\
\text { ndeu no total }\end{array}$ & $\begin{array}{l}\text { ção no processo, } \\
33 \text { mil alunos no }\end{array}$ \\
\hline
\end{tabular}

$27,2 \%$ do grupo de 25 a 29 anos e $25,5 \%$ do de 30 anos e mais. No ensino médio, quereúnea mai oria dos integrantes do grupo etário de 18 a 24 anos (53,3\%), já está francamente defasado e em idade de freqüentar a EJA, permanecia no ensino mé dio regular. Na faixa de 25 a 29 anos a mai or proporção $(29,4 \%)$ também permaneciano ensino médio regular, assim como $17,6 \%$ do grupo de 30 anos e mais. Dessa forma, ainda que os Censos Escolares só abranjam parte da EJA, parecemanifestar-se uma retenção marcante degrupos de idadeel evada no ensino regular, apesar da faculdade legal de sair dele. Sendo a opção voluntária, parte ponderável do alunado pareceeleger a permanência no ensi no regular, apesar da seriação, do custo de oportunidade resultante da idade mais avançada e de outros possíveis fatores.

Ademais, comparando os grupos de estudantes por idade com a população nacional recenseada, verifica-se que o grupo de setea quatorzeanos estava praticamente todo na escola. Dos 15 aos 17 anos, 88,1\% estavam matriculados, porém só $38,3 \%$ no nível de ensino adequado, isto é, no ensino médio regular ou da modal idade educação de jovens e adultos. Já o grupo de 18 a 24 anos, correspondenteem princí pio aos cursos superiores de graduação, estava majoritariamente no ensino fundamental eno ensino médio (total de 43,9\%). Em outros termos, apesar do seu baixo nível médio de escol aridade, a população brasilei ra permanecelongo tempo na escola, persistenelae opta pelo ensino regular, mesmo fora da idade. O atraso crônico, em grandeparte provocado pel o baixo grau de eficiência do sistema, comal tas taxas dereprovação edeafastamento por abandono, representa, portanto, perdas sociais e econômi cas notáveis.

Para atestar isso, basta observar os números absolutos. Em 2000, o Brasil contava com 9.425 al unos de 15 a 17 anos, matriculados em algum nível ou modalidade de 
ensino, estando 3.565 no ensino médio re gular. Considerando que, pelo Censo Demográfico de 2000 , a população dessa faixa era de 10.703 mil habitantes, se não houvesse distorção série/i dade, quase toda essa população estaria não só na escola, como concluindo o ensino médio aos 17 anos de idade. Em outras palavras, a escol arização da faixa etária estaria próxima da dos países desenvolvidos. Por outro lado, a escolarização do grupo de 18 a 24 anos era el evada, mas em grande partecom al unos defasados. Portanto, o Brasil, se tivesse uma educação plenamente eficiente, com os fluxos discentes ordenados, seria um país com escolaridade fundamental universal izada, quase $90 \%$ dos adol escentes no ensino médio e um quinto da população jovem na educação superior. Assim, há muito mais vagas ocupadas que crianças ejovens, evidenciando enorme desperdício de vidas e recursos. É bem verdade que pode haver alta eficiência sem el evados graus de qual idade e democratização, embora o contrário seja extremamentedifícil, para não dizer impossível.

\section{Área cinzenta: ensino noturno e EJA}

Buscando uma aproximação da resposta à pergunta anterior sobre os al unos que se dirigem à educação de jovens e adultos, a Tabela 4 focal iza a distribuição etária do al unado por nível de ensino e modalidade deeducação.

Consi derando quea idade recomendada para conclusão do curso médio é de 17 anos, mais da metade dos al unos está atrasada. Mais ainda, podemos considerar que essa el evada proporção estavaà bei ra da idade mínimalegal deconclusão do curso médio, podendo deslocar-se, caso desejasse, para a educação de jovens e adultos. Os números se mantiveram estáveis no período observado, talvez com tendência de declínio ao final. Como o ensino médio éo

Tabela 4 - Distribuição percentual das matrículas por faixa de idade, segundo o nível de ensino e modalidade de educação e ensino - Brasil - 1998-2002

\begin{tabular}{|c|c|c|c|c|c|}
\hline \multirow{2}{*}{$\begin{array}{l}\text { Matrícula por níveis, } \\
\text { modalidade e idade }\end{array}$} & \multicolumn{5}{|c|}{ Anos } \\
\hline & 1998 & 1999 & 2000 & 2001 & 2002 \\
\hline Ensino médio regular (a) & 6.969 & 7.769 & 8.193 & 8.398 & 8.711 \\
\hline 18 anos e mais (b) & 3.752 & 4.290 & 4.562 & 4.515 & 4.478 \\
\hline $\mathrm{B} / \mathrm{a}(\%)$ & 53,8 & 55,2 & 55,7 & 53,8 & 51,4 \\
\hline Ensino médio, EJA* (c) & 517 & 657 & 873 & 897 & 874 \\
\hline 18 anos e mais $(d)$ & $\cdots$ & $\cdots$ & 831 & 951 & 843 \\
\hline 19 anos e mais $(d)$ & 450 & $\cdots$ & $\cdots$ & $\cdots$ & $\ldots$ \\
\hline 20 anos e mais $(d)$ & $\cdots$ & 546 & $\cdots$ & $\cdots$ & $\cdots$ \\
\hline $\mathrm{D} / \mathrm{c}(\%)$ & 87,0 & 83,1 & 95,2 & 96,4 & 96,5 \\
\hline Ensino fundamental regular (e) & 35.793 & 36.060 & 35.718 & 35.298 & 35.150 \\
\hline 15 anos e mais (f) & 8.473 & 8.474 & 8.384 & 7.955 & 7.578 \\
\hline Fle $(\%)$ & 23,7 & 23,5 & 23,5 & 22,5 & 21,6 \\
\hline Ensino fundamental, EJA * (g) & 2.082 & 2.112 & 2.272 & 2.637 & 2.788 \\
\hline 18 anos e mais $(\mathrm{h})$ & $\cdots$ & $\cdots$ & 1.740 & 2.081 & 2.228 \\
\hline 19 anos e mais $(h)$ & 1.284 & $\cdots$ & $\cdots$ & $\cdots$ & \\
\hline 20 anos e mais $(\mathrm{h})$ & $\cdots$ & 1.296 & $\cdots$ & $\cdots$ & \\
\hline $\mathrm{H} / \mathrm{g}(\%)$ & 61,7 & 61,4 & 76,6 & 78,9 & 79,9 \\
\hline
\end{tabular}


desembocar da educação básica, as repetições e os abandonos se acumulam, gerando números típicos de sistemas educacionais com amplo acesso, mas com dificuldades na eficiência ena qual idade.

Por sua vez, a EJA, no mesmo nível médio, apresenta uma proporção mais elevada de al unos mais vel hos. Embora os limites estabelecidos pel os Censos Escol ares sejam diversos do ensino regular etenham variado ao longo da série histórica anal isada, a proporção deal unos defasadosémuito superior, até por imposição legal. Ou seja, por um lado, o ensino regular abriga mai oria dealunos com distorção série/idade, enquanto, por outro lado, a EJA, segundo o seu caráter, éo locus legal (formal, mas não necessariamente real ) para os que buscam uma segunda oportunidade de escolarização. A parentemente, pois, háuma superposição de funções entreo ensino regular ea educação dejovens eadultos, uma espécie de zona cinzenta, pel a qual ambos recebem al unos que se atrasaram na escolaridade. A proximidade entre os percentuais de al unos acima de 17 anos de idadeno ensi no médio regular eno período noturno sugereque o ensino médio regular à noite, embora geral menteseriado, podeestar abrigando al unos que, ti pi camente, estariam na educação dejovens eadultos, conformea Tabela 5. No caso das séries iniciais do ensino fundamental, não severifica tal proximidade, que, por sua vez, é reduzida para as séries finais do mesmo nível de ensino.

Evidências, no sentido de queo ensino regular noturno abriga al unos que poderiam estar na EJA, também podem ser encontradas na Tabela 6 , em queapareceo perfil etário dos concluintes do ensino fundamental e médio regulares. A distribuição por idadedos concluintes do ensino fundamental emédio regular indica que uma grande parte dos mesmostermina onível deensino muitoalém da idade. No período noturno a concentração ocorreu nas faixas de idade mais el evadas. No primeiro caso, $99,3 \%$ dos alunos terminaram o curso em idade igual ou

Tabela 5 - Percentual das matrículas no turno da noite, segundo o nível e a modalidade de educação e ensino - Brasil - 2002

\begin{tabular}{|l|c|c|c|}
\hline \multicolumn{1}{|c|}{ Níveis e modalidades } & Total & Turno da noite & $\begin{array}{c}\text { \% sobre a matrícula } \\
\text { total }\end{array}$ \\
\hline Ensino médio regular & 8.711 & 4.255 & 48,8 \\
\hline Ensino fundamental regular $\left(5^{\mathrm{a}}-8^{\mathrm{a}}\right)$ & 15.770 & 2.479 & 15,7 \\
\hline Ensino fundamental regular $\left(1^{\mathrm{a}}-4^{\mathrm{a}}\right)$ & 19.380 & 574 & 3,0 \\
\hline
\end{tabular}

Fonte dos dados originais: MEC/Inep/Seec, Censos Escolares. Números absolutos em milhares.

superior a 15 anos, queéo limiteetário mínimo para conclusão do ensino fundamental. No segundo caso, a proporção foi menor, sendo provável que cerca de dois terços dos alunos tenham concluído com idade superior àquela facultada para $\mathrm{E}$ EJA.

Os dados da Tabela 6 indicam que, apesar das facilidades legais de concluir o curso possivelmente mais cedo, com freqüência num regime desseriado, parteconsiderável dos alunos persistia no ensino regular, supostamente mais demorado e mais difícil. Se considerarmos o volume muito mai or da matrícula no ensino reguIar do que na EJA, pode-se afirmar que a maioriatinha preferência pelo ensino regular noturno (4,3 mil hões de um total de 8,4 milhões no ensino médio regular contra menos deum mi lhão nos cursos presenciais com aval iação no processo, em 2001).
No ano de 2001, concluíram o ensino fundamental regular 2.707.683 al unos, dos quais apenas 89.446 não apresentavam defasagem idade/série, e outros 449.356 concluíram o ensi no fundamental, modal idade educação de jovens eadultos.

Somando-se a esses os reprovados na primeira série do ensino médio regular e os afastados por abandono na primeira sé rie do ensino médio regular, tem-se um total de 3.651.535. A matrícula na primeira série do ensino médio, no ano de 2002, por sua vez, reunia 3.481.556 al unos e as matrículas no ensino médio, modalidade EJA, outros 906.793, num total de 4.388.349 matrículas.

Os números citados indicam que, do total de matrículas no primeiro ano do ensino médio, apenas pouco menos de dois terços $(61,7 \%)$ éconstituída pel os integrantes 
Tabela 6 - Distribuição percentual dos concluintes do ensi no fundamental e médio regulares, por faixa etária - Brasil - 2001

\begin{tabular}{|l|r|r|r|r|r|}
\hline \multicolumn{4}{|c|}{ Ensino fundamental } & \multicolumn{3}{c|}{ Ensino médio } \\
\hline \multicolumn{1}{|c|}{ Faixa etária } & \multicolumn{1}{|c|}{ Total } & Turno da noite & Faixa etária & Total & Turno da noite \\
\hline Até 14 & 3,3 & 0,7 & Até 16 & 0,4 & 0,2 \\
\hline 15 a 17 & 69,6 & 32,5 & 17 a 19 & 51,2 & 37,2 \\
\hline 18 a 19 & 14,6 & 26,8 & 20 a 21 & 23,4 & 27,3 \\
\hline 20 a 24 & 7,6 & 22,5 & 22 a 24 & 13,8 & 18,9 \\
\hline 25 e mais & 4,9 & 17,5 & 25 e mais & 11,2 & 16,4 \\
\hline Total & 100,0 & 100,0 & Total & 100,0 & 100,0 \\
\hline
\end{tabular}

Fonte dos dados originais: MEC/Inep/Seec, Censos Escolares. Números absolutos em milhares.

do fluxo escolar regular, ou seja, os concluintes do ensino fundamental. Mais ainda, uma ínfima parcela de 2,04\% dos alunos estána idade condizentecom a série freqüentada.

\section{Por que não EJA?}

Essa preferência nos conduz a indagações sobre os motivos de tal persistência, como: seria mais el evado o prestígio social do ensino regular, seriado? A educação de jovens e adultos seria vista por uma parte dos al unos como uma educação de segunda classe, estigmatizada talvez pel o mercado de trabal ho? No caso do ensino médio, essa educação seria insuficiente para competir por vagas dos cursos superiores, sendo preferível investir mais tempo no ensino regular? Por outro lado, o ensi no regular noturno apresentaria facilidades e adaptações à realidade do adulto, detal modo queconcorreria demanei ra bem-sucedida com a educação dejovens e adultos? Haveria fal ta de oferta pública e gratuita de educação de jovens e adultos? A educação de jovens e adultos seria subfinanciada, considerando que o seu menor poder de captação de verbas em face do ensino regular, a exemplo do Fundef? Existiriam indícios de que as condições de ensino seriam inferiores para a educação de jovens e adultos? Seria a educação de jovens e adultos uma opção subutilizada para democratizar a educação brasileira? Em caso positivo, por quê?
Essas questões, como as anteriores, só em parte podem ser respondidas com os dados dos Censos Escolares, ficando como sugestões para ulteriores pesquisas. Entretanto, é possível recolher al guns indícios a partir dos números disponíveis. Em primeirolugar, pode-secotejar o perfil da escol aridade dos professores, cujos dados são agregados. Somando o ensi no fundamental eo ensino médio na modalidadeEJA, verificase que o porcentual de funções docentes ocupadas por pessoal de nível superior era de $67,5 \%$ em 2000 , contra $57,0 \%$ do ensino regular nos níveis correspondentes. A proporção de funções docentes desempenhadas por profissionais denível médio era de $30,2 \%$ contra $39,5 \%$ e o percentual de professores com o ensino fundamental era ligei ramente inferior para a educação de jovens e adultos, ou seja, 2,3\%, contra 3,6\% do ensino regular. Portanto, havia superioridade da titulação do magistério (Inep, 2001).

Quanto à relação média de al unos por função docente, os valores foram de 11,2 para o ensino fundamental e médio regulares e de 30,0 para a educação de jovens e adultos. Esta média, considerando que se trata de ensino presencial, érelativamente el evada, em face da pluralidade de componentes curriculares nas últimas séries do ensino fundamental eno nível médio (a relação para a quinta à oitava sérieera de 10,2 e para o ensino médio, de 19,0). Todavia, o ensino regular tem um grande contingente de crianças, que exige menor número médio de alunos por função docente. 
Assim, de modo geral, não parece ter havido, no período, escassez de vagas públicas tanto no ensino regular quanto na educação de jovens e adultos. Ao contrário, os indícios são de que ocorreu um importante esforço de expansão, tanto pelos Estados quanto pel os municípios e, ainda, pel o terceiro setor.

Por outro lado, a taxa bruta de concluintes, cal culada como o percentual daqueles que terminam o curso sobre a matrícula inicial total, deixa claro que a educação de jovens eadultos, muitas vezes desseriada, é vantajosa para aquel es que desejam terminar mais rápi do os seus estudos. Ao contrário, 0 ensino regular, geral mentecoma repetência deséries anuais, leva mais tempo parao término. Assim, considerando o ano de 2000 , a taxa bruta de concluintes para o ensino mé dio regular, mesmo com o mínimo de três séries anuais, foi de $22,4 \%$, enquanto paraa educação de jovens e adultos foi de $43,6 \%$. No ensino fundamental regular a referidataxa foi de 7,4\% no mesmo ano, indicando o progresso relativamente lento dos efetivos discentes. Já na educação de jovens eadultoso mesmo val or seelevou a 29,3\%. A questãoé, portanto, compreender por que grandeparte da popul ação estudantil busca a alternativa aparentemente mais difícil para concluir os seus estudos. Pesquisas específicas poderão aprofundar se a preferência pelo ensino regular, particularmente noturno, é ou não resultado de desvantagens da educação dejovens eadultos em geral.

\section{A geografia das desigualdades}

A distribuição regional das matrículas deixa claro a concentração no SudesteeSul, concentração essa que tende a se el evar nas séries finais do ensi no fundamental eno ensino médio, quer regular, quer educação de jovens e adultos, conforme a Tabela 7 evidencia. Em outros termos, quanto mais elevado o nível deensino, mai or a concentração regional .

No entanto, os números índices referentes à variação das matrículas de 1997 a 2002 (1997 foi o primeiro ano em queaEJA foi desagregada) sugerem quea concentração regional está diminuindo (Tabela 8). Quanto à média nacional, enquanto as séries iniciais do ensino fundamental regular acompanham o decréscimo da população escolarizável, a matrícula de educação de jovens eadul tos teve aumento expressivo.

Nas séries finais do ensino fundamental regular ena EJA, as médias nacionaisforam idênticas, já quea população ruma para o cumprimento da escol aridade obrigatória de oito anos. No ensino médio, a EJA teveo maior crescimento; porém, partindo deuma

Tabela 7 - Distribuição percentual das matrículas por nível de ensino e modalidade de educação e ensino, segundo a região geográfica - 2002

\begin{tabular}{|c|c|c|c|c|c|c|}
\hline \multirow{2}{*}{ Regiões } & \multicolumn{2}{|c|}{ Ensino médio } & \multicolumn{2}{|c|}{$\begin{array}{l}\text { Ensino fundamental } \\
\qquad 5^{a}-8^{a}\end{array}$} & \multicolumn{2}{|c|}{$\begin{array}{l}\text { Ensino fundamental } \\
\qquad 1^{\mathrm{a}}-4^{\mathrm{a}}\end{array}$} \\
\hline & Regular & EJA & Regular & EJA & Regular & EJA \\
\hline Brasil & $\mathrm{N}=8.711$ & $\begin{array}{r}100,0 \\
N=874\end{array}$ & $\begin{array}{r}100,0 \\
N=15.770\end{array}$ & $\begin{array}{r}100,0 \\
N=1.435\end{array}$ & $\begin{array}{r}100,0 \\
N=19.380\end{array}$ & $\begin{array}{r}100,0 \\
N=1.353\end{array}$ \\
\hline Norte & 7,6 & 7,5 & 7,5 & 20,2 & 11,0 & 15,3 \\
\hline Nordeste & 26,5 & 20,2 & 32,6 & 23,3 & 37,0 & 57,9 \\
\hline Sudeste & 44,7 & 43,1 & 38,3 & 35,8 & 33,7 & 18,0 \\
\hline Sul & 14,0 & 18,2 & 13,4 & 14,4 & 11,6 & 5,1 \\
\hline Centro-Oeste & 7,2 & 11,0 & 8,1 & 6,2 & 6,7 & 3,6 \\
\hline
\end{tabular}

Fonte dos dados originais: MEC/Inep/Seec, Censos Escolares.

Observação: Na educação de jovens e adultos, foram considerados somente os cursos presenciais com avaliação. Números absolutos em milhares. 
basemenor. O ensino regular teveo segundo maior aumento, envolvendo oincremento de um grande contingente de matriculados. Quanto às regiões, o Norteeo Nordestefiguramfreqüentementeacima da médianacional eo Centro-Oeste, em vários casos. Com isso, tende-seareduzir os hiatos regionais.

Quanto à dependência admi nistrativa, além deuma pequena partici pação federal, tanto o ensino fundamental quanto o médio

Tabela 8 - Índices relativos às variações das matrículas por nível e modalidade de educação e ensino, segundo a região geográfica - 1997-2002

\begin{tabular}{|c|c|c|c|c|c|c|}
\hline \multirow{2}{*}{ Regiões } & \multicolumn{2}{|c|}{ Ensino médio } & \multicolumn{2}{|c|}{$\begin{array}{l}\text { Ensino fundamental } \\
\qquad 5^{a}-8^{a}\end{array}$} & \multicolumn{2}{|c|}{$\begin{array}{l}\text { Ensino fundamental } \\
\qquad 1^{\mathrm{a}}-4^{\mathrm{a}}\end{array}$} \\
\hline & Regular & EJA & Regular & EJA & Regular & EJA \\
\hline Brasil & 136 & 224 & 115 & 160 & 94 & 103 \\
\hline Norte & 153 & 275 & 128 & 167 & 102 & 192 \\
\hline Nordeste & 171 & 352 & 149 & 149 & 93 & 215 \\
\hline Sudeste & 124 & 234 & 99 & 84 & 94 & 81 \\
\hline Sul & 120 & 140 & 103 & 92 & 92 & 110 \\
\hline Centro-Oeste & 137 & 229 & 115 & 108 & 93 & 80 \\
\hline
\end{tabular}

eram oferecidos em sua mai or parte pel os Estados e municípios (Tabela 9).

Acompanhando a distribui ção constitucional e legal de competências, o ensino fundamental era oferecido predominantemente pelos municípios e o médio pelos Estados. Quanto à dependência particular, apresentou-se inferior a um décimo no ensino fundamental equaseinexpressivana EJA. No entanto, há que considerar a mencionada questão da cobertura dos censos. Sua participação foi maior justamenteno setor quemais cresceu o ensino médio, viaEJA.

Os númerosíndices, por sua vez, reve lam a dinâmica das matrículas no mesmo período. A Tabel a 10 mostra que tem ocorrido estadualização do ensino médio e municipalização do ensino fundamental, tendência pronunciada a partir da implantação do Fundef, em 1998.

Tabela 9 - Distribuição percentual das matrículas por nível e modalidade de educação e ensino, segundo a dependência administrativa - 2002

\begin{tabular}{|c|c|c|c|c|c|c|}
\hline \multirow{2}{*}{$\begin{array}{l}\text { Dependência } \\
\text { Administrativa }\end{array}$} & \multicolumn{2}{|c|}{ Ensino médio } & \multicolumn{2}{|c|}{$\begin{array}{l}\text { Ensino fundamental } \\
\qquad 5^{a}-8^{a}\end{array}$} & \multicolumn{2}{|c|}{$\begin{array}{l}\text { Ensino fundamental } \\
\qquad 1^{\mathrm{a}}-4^{\mathrm{a}}\end{array}$} \\
\hline & Regular & EJA & Regular & EJA & Regular & EJA \\
\hline Total & $\begin{array}{r}100,0 \\
N=8.711\end{array}$ & $\begin{array}{r}100,0 \\
N=907\end{array}$ & $\begin{array}{r}100,0 \\
N=15.770\end{array}$ & $\begin{array}{r}100,0 \\
N=2.788\end{array}$ & $\begin{array}{r}100,0 \\
N=19.380\end{array}$ & $\begin{array}{r}100,0 \\
N=1.353\end{array}$ \\
\hline Federal & 0,9 & 0,1 & 0,1 & 0,2 & 0,0 & 0,0 \\
\hline Estadual & 83,8 & 72,6 & 57,5 & 55,8 & 26,7 & 22,0 \\
\hline Municipal & 2,4 & 3,0 & 32,6 & 38,4 & 64,6 & 76,6 \\
\hline Particular & 12,9 & 24,3 & 9,8 & 5,6 & 8,7 & 1,4 \\
\hline
\end{tabular}

Fonte dos dados originais: MEC/Inep/Seec, Censos Escolares.

Observação: Em EJA, foram considerados somente os cursos presenciais com avaliação no processo. 
Acompanhando a distribuição constitucional elegal decompetências, o ensino fundamental era oferecido predominantemente pelos municípios e o médio pelos Estados. Quanto à dependência particular, apresentou-seinferior a um décimo no ensino fundamental equase inexpressiva na EJA. No entanto, há que consi derar a mencionada questão da cobertura dos censos.
Sua participação foi mai or justamenteno setor quemais cresceu o ensino médio, viaEJA.

Os números índices, por sua vez, reveIam a dinâmica das matrículas no mesmo período. A Tabela 10 mostra quetem ocorrido estadualização do ensino médio e municipalização do ensino fundamental, tendência pronunciada a partir da implantação do Fundef, em 1998.

Tabela 10 - Índices relativos às variações das matrículas por nível e modalidade de educação e ensino, segundo a dependência administrativa - 1997-2002

\begin{tabular}{|l|c|r|r|r|r|r|}
\hline \multirow{2}{*}{$\begin{array}{c}\text { Dependência } \\
\text { Administrativa }\end{array}$} & \multicolumn{2}{|c|}{ Ensino médio } & \multicolumn{2}{c|}{$\begin{array}{c}\text { Ensino fundamental } \\
\mathbf{5}^{\mathbf{a}}-\mathbf{8}^{\mathbf{a}}\end{array}$} & \multicolumn{2}{c|}{$\begin{array}{c}\text { Ensino fundamental } \\
\mathbf{1}^{\mathbf{a}}-\mathbf{4}^{\mathbf{a}}\end{array}$} \\
\cline { 2 - 7 } & Regular & EJA & Regular & EJA & Regular & EJA \\
\hline Total & 136 & 224 & 115 & 160 & 94 & 103 \\
\hline Federal & 70,6 & 84,6 & 100,8 & $\mathbf{4 6 6 , 2}$ & 62,3 & 40,0 \\
\hline Estadual & 157 & 255 & 98 & 85 & 58 & 58 \\
\hline Municipal & 58 & 142 & 195 & 249 & 128 & 287 \\
\hline Particular & 89 & 172 & 91 & 54 & 86 & 76 \\
\hline
\end{tabular}

Fonte dos dados originais: MEC//nep/Seec, Censos Escolares.

Observação: Na educação de jovens e adultos foram considerados os cursos presenciais com avaliação no processo. Os números em negrito situam-se acima da média geral.

A dependência particular, nas proporções em queécaptada pelos Censos Escolares, vem perdendo terreno em todos os níveis deensino emodal idades de educação, exceto no ensino médio, EJA, masnovamente se deve atentar para a cobertura censitária. O decréscimo mai or ocorreu no ensino fundamental, EJA, que certamente atende, em grande parte, a al unos socialmente menos privilegiados. Dessemodo, o poder público vemaparentementedesempenhando umpapel coerente com os mandamentos constitucionais vigentes. No entanto, ao aumentar a abrangência dos censos escolares, em vez de recuo, provavel mente se verificará grande expansão, graças em especial ao terceiro setor. Isso revel aria que, em virtude da opção preferencial pelo ensino fundamental reguIar, a EJA teria se tornado amplo território da sociedade civil, em colaboração com os poderes públicos.

Os dados do Censo Escolar contrariam a suposta fal ta de oferta dematrícula, poiso crescimento das dependências admi nistrativas estadual emunicipal apresentou nível elevado. No ensi no médio regular, tendo o ano de 1997 como base 100, a dependência estadual chegou a 157 em 2002, enquanto a particular se reduziu para 89. Nos cursos presenciais de ensino médio da modalidade EJA, a matrícula estadual no mesmo período atingiu 255 e a municipal, 142, sempre tendo 1997 como base 100. O ensino particular teve incremento para 172 no período, considerando só a área coberta pelo Censo. Passando às séries finais do ensino fundamental, a munici palização da matrícula foi notória, enquanto a oferta privada recuou. Por sua vez, os cursos presenciais correspondentes, com avaliação no processo, em educação de jovens e adultos, experimentaram aumento de matrícula, sobretudo na área municipal. $\mathrm{O}$ incremento mais expressivo nas matrículas das séries finais da educação de jovens e adultos encontra-se nas insti tuições federais de ensi no. No entanto, em que pese o incremento de 466,2, o total de matrículas nessas instituições situa-se abaixo de $1 \%$ do total . 


\section{Conclusões}

Buscando uma aproximação às perguntas anteriores, pode-se observar:

1. Noâmbi to das matrículas registradas pelos Censos Escolares, o ensino médio, via EJA, apesar de ter uma basede matrículas muito menor que o regular, no período observado, apresentou ritmo de crescimento mais rápido, podendo indicar que um número maior de al unos tenha se valido da vantagem legal de concluir essenível deensino aos 18 anos de idade, sem passar pela rígida seriação anual. Apesar disso, mesmo que se considere o sub-registro de matrículas de EJA, grande parte dos al unos parece preferir o ensino regular, em que pese a sua idade.

2. A presença detantos al unosqueconcluem o ensino regular, tanto em nível fundamental quanto médio, aponta para uma área cinzenta onde se superpõe a atuação tanto do ensino regular quanto da EJA. O primeiro, apesar de usualmente seriado, em especial no período danoite, por motivos tal vez ligados ao prestígi o social, capta grande partedo al unado que, pela Lei, poderia optar por uma educação que, segundo as expectativas, aproveitassea sua bagagem de expe riências. No caso do ensino médio, é possível que a preparação para os processos sel etivos à educação supe rior conduza à procura pelo ensino regular, conforme a pesquisa exploratória citada. Esta opção de número expressivo de alunos, possivelmente com objetivos mais ambiciosos, pelo ensino regular, pode confirmar a hierarquização das modalidades educacionais, nos termos da literatura antes referida. Mais sainda, revela que as decisões dos alunos são racionais do ponto de vista dos seus planos educacionais e de carreira. Desse modo, currículos e modalidades diferenciados têmgraus diferentes de prestígio e também variadas possi bilidades na vida social eno mercado de trabal ho, rel acionadas às origens sociais dos al unos eà suatrajetória escolar, interrompidae depois retomada. O que poderia ser racional para o poder público, se a
EJA tiver custo/aluno mais baixo, pode não ser racional para os al unos mais exigentes.

3. Como os Censos Escolares não abrangem todo o universo daEJA, fal ta uma visão clara sobre os impactos daredução dos limites etários legais. Dequalquer modo, a falta de relativa atratividade da EJA reitera a preocupação com a sua qualidade e capacidade de democratização. Conformea perspectiva sociológica do conflito, podetratar-sedeescolarização pobre para al unos pobres, reforçando as disparidades sociais, nos termos da análise sociológica dos currículos. Podetambém ser, subjetivamente, um caso de estigmatização de uma modalidade educacional, em virtude do status socioeconômico dos al unos que afreqüentam. Ou podehaver umaconcorrência defatores subjetivos eobjetivos que se reforçam mutuamente.

4. A concentração regional das matrículas étanto mai or quanto mais elevado o nível de ensino, todavia, a evolução dos números evidencia a diminuição progressiva do hiato entre as regiões relativamente mais e menos desenvolvidas. Ao mesmo tempo, tem ocorrido estadual ização do ensino médio e municipalização do ensino fundamental. Quanto à de pendência administrativa, o Poder Público tem conseguido ampliar substancialmentea matrícula a ponto defazer regredir a participação particular, exceto no quetange ao ensino médio via EJA. Entretanto, o aumento da cobertura do Censo Escolar poderá indicar que, ao contrário, a EJA, em grande parte, está a cargo do denominado Terceiro Setor.

5. Em vista da superposição entre o ensino regular, em especial no período noturno, e a EJA, constituindo a mencionada área cinzenta, os dados sugerem a necessidade de responder a, pel o menos, dois desafios:

a) o de criar uma escola para adolescentes ejovens, com suas peculiaridades e identidade própria, atendendo às necessi dades do contexto social, inclusive do trabal ho (cf. Braslavsky, 2002);

b) o de concretizar, com eficiência e qualidade, a EJA, diferente, 
mas não inferior, para democratização das oportuni dades educacionais voltadas para numerosos grupos etários da população nacional.

Conformea refl exão de Dubet (2003), quanto mais a escola intensifica o seu rai o de ação, mais ela exclui, sendo a exclusão não só uma categoria do sistema e dos processos gl obais, mas também uma das dimensões da experiência escolar dos al unos. Todavia, isso não é um determi nismo que impeça as políticas públicas de reduzir a exclusão, mas, ao contrário, a indicação do dever detornar as oportunidades educacionais redutoras, antes queamplificadoras, das diferenças sociais.

\section{Referências bibliográficas}

ALFABETIZAÇÃO SOLIDÁRIA. Sala de aula; onde o Brasil tem futuro. 2003.

BARRÈRE, Anne; SEMBEL, Nicolas. Sociologie de l'Éducation. Paris: Nathan, 2002.

BERNSTEIN, Basil. Class, codes and control. London: Routledge and Kegan Paul, 1977. v. 4: Thestructuring of pedagogic discourse.

BRASLAVSKY, Cecília. A educação secundária. Mudança ou imutabilidade? Análise e debatede processos europeuse latino-americanos contemporâneos. Brasília: Unesco, 2002.

CARNOY, Martin; LEVIN, Henry M. Escola e trabalho no Estado democrático. São Paulo: Cortez, 1987.

CICOUREL, Aaron V.; KITSUSE, John I. The school as a mechanism of social differentiation. In: KARABEL, Jerome; HALSEY, A. H. Power and ideology in education. New York: Oxford University Press, 1978. p. 282-292.

CLARK, Burton R. Adaptação das organizações eval ores precários. In: ETZIONI, Amitai. Organizações complexas: estudo das organizações em face dos problemas sociais. São Paulo: Atlas, 1978. p. 161-168.

CUNHA, Célio da. A LDB Darcy Ribeiro ea educação fundamental. In: GOMES, Candido Alberto (Org.). A nova LDB: uma lei deesperança. Brasília: Universa/Unesco, 1998. p. 4972.

DUBET, François. A escola e a exclusão. Cadernos de Pesquisa, São Paulo, n. 119, p. 2945, jul. 2003.

DUBET, François; MARTUCCELLI, Danilo. À l'école: sociologie del'experience scolaire. Paris: Seuil, 1996.

GIROUX, Henry. Teoria crítica e resistência em educação: para além das teorias da reprodução. Petrópolis: Vozes, 1986.

GOMES, Candido Alberto. A educação em perspectiva sociológica. 3. ed. São Paulo: EPU, 1994.

. 0 ensino médio no Brasil ou a história do patinho feio recontada. Brasília: Universa/ Unesco, 2000.

Uma lei de esperança: estudo geral sobre a nova Lei de Diretrizes e Bases. In: GOMES, Candido Alberto (Org.). A nova LDB: uma lei de esperança. Brasília: Universa/ Unesco, 1998. p. 49-72. 
GOMES, Candido Alberto; CARNIELLI, Beatrice. Expansão do ensino médio: temores sobre a educação dejovens e adultos. Cadernos de Pesquisa, São Paulo, n. 119, p. 47-69, jul. 2003.

INSTITUTO NACIONAL DE ESTUDOS E PESQUISAS EDUCACIONAIS. Saeb/95: Relatório Final. Brasília: MEC/Bird/Projeto Nordeste, 1998.

KERCKHOFF, Alan C. Stratification processes and outcomes in England and the U.S. American Sociological Review, v. 39, n. 6, p. 789-801, dez. 1974.

RIORDAN, Cornelius. Equality and achievement. 2. ed. Upper SaddleRiver, New Jersey: Pearson, Prentice Hall, 2004.

ROSENBAUM, James E. Making inequality: the hidden curriculum of high school tracking. New York: John Wiley and Sons, 1976.

SERVIÇO SOCIAL DA INDÚSTRIA (SESI). Departamento Nacional. Relatório de pesquisa do estudo custo aluno/ano: Programa SESI Educação do Trabal hador. Brasília: SESI-DN, 2001.

SNYDERS, Georges. Pedagogia progressista. Coimbra: Almedina, 1974.

WEBER, Max. Economy and society: an outline of interpretative sociology. New York: Bedminster, 1968.

WEST, Cornel. Thenew cultural politics of difference. In: HALSEY, A. H. (Org.). Education: culture, economy, and society. Oxford: Oxford University Press, 1997. p. 509-519.

YOUNG, Michael F. D. An approach to the study of curriculum as socially organized knowledge. In: YOUNG, Michael. F. D. (Org.). Knowledge and control: new directions for the sociology of education. London: Collier MacMillan, 1971. p. 19-46.

Curriculum and democracy: lessons froma critiqueof the "new sociology of education". London: Centrefor Vocational Studies, Institute of Education, University of London, 1988.

\section{Fontes dos dados}

INSTITUTO BRASILEIRO DE GEOGRAFIA E ESTATÍSTICA. Censo demográfico 2000 resultados do universo. Tabela - População residente, por situação do domicílio e sexo, segundo os grupos deidade- Brasil. Disponível em: http://www.ibge.net/home/estatistica/ populacao/censo2000/tabelabrasil111.shtm. Acesso em: 7 ago. 2002.

INSTITUTO NACIONAL DE ESTUDOS E PESQUISAS EDUCACIONAIS. Sinopse estatística da educação básica: censo escolar 97. Brasília: Inep, 1998.

. Sinopse estatística da educação básica: censo escolar 98. Brasília: Inep, 1999.

. Sinopse estatística da educação básica: censo escolar 99. Brasília: Inep, 2000.

. Sinopse estatística da educação básica: censo escolar 2000. Brasília:Inep, 2001.

. Sinopse estatística da educação básica: censo escolar 2001. Brasília: Inep, 2002.

. Sinopse estatística da educação básica: censo escolar 2002. Brasília: Inep, 2003. 
Candido Alberto Gomes, doutor em Educação pela Universidade da Califórnia, Los Angel es, EUA, é professor titular da Universi dade Católica de Brasília (UCB), consultor da Unesco e coordenador do Observatório de Violências nas Escolas - Brasil (Unesco/ UCB).

clgomes@terra.com.br

Beatrice Laura Carnielli, doutora pela Universidade Federal do Rio deJaneiro (UFRJ), é professora adjunta do mestrado em Educação da UniversidadeCatólica de Brasília (UCB). beatricelaura@terra.com.br

Isolêta Rodrigues Assunção égraduanda de Pedagogia da UCB.

\section{Abstract The expansion of secondary education and the education for adults and youths: a neglected alternative of democratization?}

This paper focuses the recent expansion of secondary education by means of regular and adult education. Since there is a high degree of age-grade distortion in its population, this work studies the effects of the reduction of age limit allowed for students application for adult education. Its framework emphasizes that education is socially stratified, resulting in a hierarchy of curricula and alternatives on the basis of social prestige and occupational and social perspectives. School Census data reveal that the expansion in adult education enrolment was faster in 1998-2002 than in regular education, although the absolute number of students in the former was small. Therefore, despite legal change, even ol der students have preferred regular education, suggesting competition between regular night school and adult education. Probably, as a result of lower social prestige, lower quality and limited acceptance by the labor market, adult education has been a neglected alternative for educational democratization, in spite of its flexibility.

Keywords: secondary education; adult education; educational democratization; agegrade distortion; night school.

Recebido em 20 de fevereiro de 2004.

A provado em 16 de março de 2004. 